\title{
Therapeutic use of the rebound effect of modern drugs: "New homeopathic medicines"
}

\author{
MARCus ZULIAN TEIXEIRA ${ }^{1 *}$ \\ ${ }^{1} \mathrm{MD}$, PhD, Postdoctoral Student of the Department of Obstetrics and Gynecology, Faculdade de Medicina da Universidade de São Paulo (FMUSP). Coordinator of the Elective Discipline Fundamentals of Homeopathy \\ (MCM0773), FMUSP, São Paulo, SP, Brazil
}

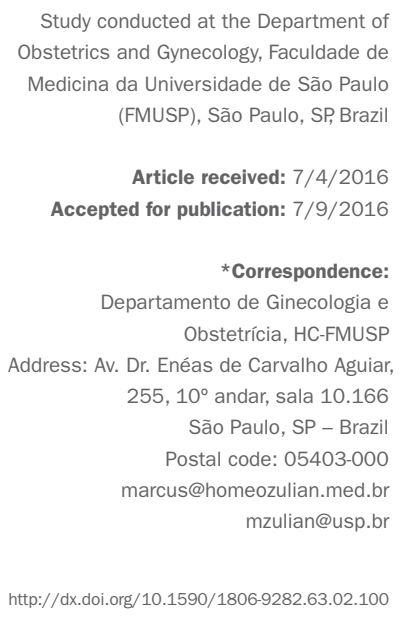

\section{SUMMARY}

The homeopathic treatment is based on the principle of therapeutic similitude, employing medicines that cause certain disorders to treat similar manifestations, stimulating a reaction of the organism against its own ailments. The occurrence of this secondary reaction of the organism, opposite in nature to the primary action of the medicines, is evidenced in the study of the rebound (paradoxical) effect of several classes of modern drugs. In this work, in addition to substantiate the principle of similitude before the experimental and clinical pharmacology, we suggest a proposal to employ hundreds of conventional drugs according to homeopathic method, applying the therapeutic similitude between the adverse events of medicines and the clinical manifestations of patients. Describing existing lines of research and a specific method for the therapeutic use of the rebound effect of modern drugs (http://www.newhomeopathicmedicines.com), we hope to minimize prejudices related to the homeopathy and contribute to a broadening of the healing art.

Keywords: homeopathy, pharmacology, pharmacodynamic action of homeopathic remedy, law of similars, rebound effect, new homeopathic remedy.

\section{INTRODUCTION}

The homeopathic model for the treatment of disease is based on four assumptions: (i) the principle of healing by similars; (ii) pathogenetic experimentation of medicines in health humans; (iii) use of ultra-diluted (dynamized) medicines; and (iv) prescription of individualized medicines. Although great importance is attributed to dynamized medication (produced through the dilution and serial agitations of the substances), incorporated secondarily to the therapy in order to minimize possible initial symptomatic aggravations derived from the application of the principle of healing by similars, the first two assumptions are the foundation of the homeopathic episteme, with individualized homeopathic medicine (chosen according to the totality of characteristic signs and symptoms) holding the inherent condition for awakening the organism's healing reaction. ${ }^{1}$

In Ancient Greece, Hippocrates taught that diseases could be treated by the principles of "contraries" (contraria contrariis curantur) or "similars" (similia similibus curantur), recommendations which were followed by several exponents of subsequent medical schools. ${ }^{2}$
At present, the "principle of contraries" is applied to a large part of conventional therapy, which uses medicines with primary action against (anti-) the signs and symptoms of diseases (palliative or antipathic drugs) in order to minimize or neutralize their manifestations. On the other hand, the "principle of similars" is used by homeopathic therapy, which uses medicines that cause similar signs and symptoms (homeo) to diseases in order to stimulate a secondary action or reaction by the organism against its own disorders.

Since 1998, we have been scientifically grounding the principle of therapeutic similarity through the systematic study of the "rebound effect" of modern drugs ("paradoxical reaction" of the organism), ${ }^{2-12}$ showing the manifestation of this secondary and opposite reaction of the organism after the primary action of numerous classes of drugs. At the end of 2013, we published a review on the rebound effect of drugs in this journal, ${ }^{13}$ showing the extent of the phenomenon and alerting health professionals about the serious consequences that this unknown adverse event can cause.

In the last decade, exponents of modern pharmacology have suggested a therapeutic strategy entitled "para- 
doxical pharmacology," similar to the one propagated by homeopathy for over two centuries, proposing the use of conventional drugs that cause an exacerbation of the disease in the short term in order to treat the same disease in the long term. ${ }^{14-26}$ Similarly, since the beginning of our studies, we have been suggesting the use of modern drugs in accordance with the principle of therapeutic similarity, proposing the use of drugs that cause adverse events similar to the manifestations of diseases in order to treat them homeopathically, using the rebound effect (paradoxical reaction) in a curative manner. $2,3,9,10,11,13,27-33$

In this study, we elaborate on this proposal in accordance with the assumptions of the homeopathic model and the fundamentals of modern pharmacology, describing existing research and a specific methodology for the therapeutic application of the rebound effect of modern drugs, suggesting the use of this practice in a complementary and adjuvant manner ${ }^{34}$ in a myriad of diseases and syndromes. As such, we hope to contribute to medical knowledge, minimizing prejudice related to homeopathy and encouraging an expansion of the art of healing.

\section{THE PRINCIPLE OF SIMILARITY ACCORDING TO THE HOMEOPATHIC MODEL}

In the development of the homeopathic model, Samuel Hahnemann (1755-1843) used the phenomenological method of qualitative research to describe the effects of drugs on human physiology and substantiate the principle of similarity. Based on the study of the pharmacological properties of dozens of medicinal substances of his time, in which a "secondary action or reaction of the organism after primary drug action" was observed, ${ }^{35}$ Hahnemann enunciated an aphorism to explain the possible effects of drugs on human health:

Every agent that acts upon the vitality, every medicine, deranges more or less the vital force, and causes a certain alteration in the health of the individual for a longer or a shorter period. This is termed primary action. [...] To its action our vital force endeavors to oppose its own energy. This resistant action is a property, is indeed an automatic action of our life-preserving power, which goes by the name of secondary action or counteraction. (Organon of medicine, $\S 63)^{36}$

He exemplifies this principle describing the primary actions of medicines on various physiological systems and the consequent secondary actions or counteractions of the organism, with opposite effects to the primary physiological changes, which induce the organism to return to the state prior to the intervention (conservation force or vital reaction or life-preserving power):
(...) Excessive vivacity follows the use of strong coffee (primary action), but sluggishness and drowsiness remain for a long time afterwards (reaction, secondary action), if this be not always again removed for a short time by imbibing fresh supplies of coffee (palliative, short duration). After the profound stupefied sleep caused by opium (primary action), the following night will be all the more sleepless (reaction, secondary action). After the constipation produced by opium (primary action), diarrhea ensues (secondary action); and after purgation with medicines that irritate the bowels, constipation of several days' duration ensues (secondary action). And in like manner it always happens, after the primary action of a medicine that produces in large doses a great change in the health of a healthy person, that its exact opposite, when, as has been observed, there is actually such a thing, is produced in the secondary action by our vital force. (Organon of medicine, $\S 65)^{36}$

In order to provide clarification to readers not familiar with the homeopathic terminology, the primary actions (direct effects) of the medicines correspond to the therapeutic and adverse effects of modern pharmacology, and the secondary actions (indirect effects) of the medicines or reactions of the organism correspond to the rebound effect of drugs or paradoxical reaction of the organism, which we will describe in detail below. Similarly, the terms conservation force or vital reaction or life-preserving power correspond to the homeostatic mechanisms described by modern physiology, that is, the property of living organisms to maintain the constancy of the internal environment through automatic self-adjustments to physiological processes, ranging from simple cellular mechanisms to complex psychological functions.

Whereas this reaction of the organism (secondary and opposite reaction to the primary action of the medicine) may manifest with all types of drugs, regardless of the dose, and in any individual, Hahnemann raises the principle of similarity to the category of "natural phenomenon" (Organon of medicine, § 58, 61, 110-112). ${ }^{36}$

Proposing to administer substances to patients which arouse similar symptoms in individuals submitted to "homeopathic pathogenetic experimentation" ("pathogenetic homeopathic trials," similar to phase I pharmacological clinical trials), ${ }^{37,38}$ the principle of therapeutic similarity aims to stimulate a curative homeostatic reaction, inducing the organism to react against its own disorders.

\section{THE PRINCIPLE OF SIMILARITY IN THE LIGHT OF MODERN PHARMACOLOGY $2-13$}

Building a bridge between the principle of similarity and modern scientific rationality, hundreds of studies de- 
scribed, in recent medical literature, the occurrence of secondary and opposite reactions of the organism after the primary actions of different drugs, confirming the homeopathic postulate. As mentioned previously, this secondary action or organism's reaction, which manifests itself automatically and instinctively in order to maintain the homeostasis of the system, is described by contemporary pharmacology and physiology as the rebound effect of the drugs, or paradoxical reaction of the organism, respectively. Analogously, the primary action of the drugs cited by Hahnemann corresponds to the therapeutic, adverse and collateral effects of modern drugs.

According to evidence from experimental and clinical pharmacology, ${ }^{2-13}$ the rebound effect of modern drugs presents similar characteristics to the secondary action or the reaction of the organism described by the homeopathic model (Organon of medicine, § 59, 64, 69): ${ }^{36}$ (i) it causes an opposite reaction of the organism with greater intensity than the primary action of the drug; (ii) it occurs after the primary action of the drug as an automatic manifestation of the organism; (iii) it is independent of the drug, dose, duration of treatment or the type of symptom (illness); (iv) its magnitude is proportional to the primary action of the drug; and (v) it only manifests in susceptible individuals (idiosyncratic character).

According to the extensive literature, ${ }^{2-13}$ several studies illustrate the universality of the rebound phenomenon in relation to the distinct classes of palliative drugs (antianginal, antihypertensive, antiarrhythmic, antithrombotic, and antihyperlipidemic agents, anxiolytics, sedative-hypnotics, neurostimulants, antidepressants, antipsychotics, anti-inflammatory drugs, analgesics, diuretics, bronchodilators, anti-dyspeptics, bone antiresorptive agents, and immunomodulators, among others), showing aggravation of the signs and symptoms initially suppressed by the primary and direct action of the drug, after its discontinuation.

By definition, the rebound effect presents an intensity and/or frequency a few times higher than the corresponding baseline symptoms suppressed by the primary action of the antipathic drug, a characteristic that distinguishes the rebound phenomenon from the natural reappearance of chronic symptoms after the end of treatment. Epidemiological studies show that this magnitude can cause severe and fatal events after the suspension of certain classes of drugs (antithrombotics, antidepressants, bronchodilators, anti-dyspeptics and immunomodulators, among others). ${ }^{4-13}$

The rebound effect manifests itself at different intervals (hours to weeks) after the exhaustion of the biological effect (half-life) of the drug, and its duration is also variable. De- spite the suspension or discontinuation of the drug being a prerequisite for the manifestation of the rebound effect, given that the primary action of the drug persists while the receptors are being stimulated (biological half-life), studies show that the rebound effect may also occur in the course of treatment due to therapeutic failure or the development of tolerance, tachyphylaxis or desensitization. On the other hand, a slow and gradual reduction of doses (tapering) to prevent abrupt discontinuation can minimize the occurrence of the rebound effect. ${ }^{2-13}$

In analogy to the proposal to be detailed below, reports in the literature describe the use of conventional drugs according to therapeutic similarity. Among these, we can cite the use of biphasic oral contraceptives to promote ovulation and rebound pregnancy in women with functional sterility and the use of central nervous system stimulants (methylphenidate) to treat attention deficit hyperactivity disorder (ADHD). ${ }^{39,40}$

\section{Paradoxical pharmacology ${ }^{14-26}$}

A strategy suggested by Richard A. Bond in $2001,{ }^{14}$ paradoxical pharmacology proposes the therapeutic use of the paradoxical effects of drugs (secondary reactions of the organism with the opposite nature to the primary effects of the drugs). Universal in nature, such paradoxical, bidirectional or compensatory effects appear in several classes of drugs, regardless of the dose, and affect various percentages of individuals. Although not fully elucidated, this paradoxical effect is manifested at different levels of the biological self-regulation systems, increasing the functional complexity of the entire organism, from subcellular components (channels, enzymes, receptors, transporters, organelles, etc.) to cells, tissues and organs. ${ }^{15-19}$

Present in any physiological system, these paradoxical and bidirectional effects occur due to varying mechanisms: different actions on the same receptor, due to temporal effects (for example, beta-blockers with intrinsic sympathomimetic activity); stereochemical effects (for example, salbutamol); multiple receptor targets, with or without associated temporal effects (for example, procainamide); antibody-mediated reactions (for example, heparin-induced thromboembolism); pharmacokinetic effects of competing compartments (for example, bicarbonate); interruption and non-linear effects on systems (for example, dopaminergic agents); systemic overcompensation (for example, antiretroviral therapy and immune reconstitution inflammatory syndrome); other higher level feedback mechanisms (for example, digoxin) and multilevel feedback cycles (for example, isotretinoin-associated acne fulminant), and more. ${ }^{19}$ 
As described for the rebound effect, ${ }^{2-13}$ the authors cite several examples of paradoxical and bidirectional effects of drugs in different pharmaceutical classes and physiological systems: immunomodulators (systemic corticoids and TNF- $\alpha$ inhibitors), anticancer drugs (chemotherapy, radiotherapy and arsenic), antiarrhythmics (procainamide and isoproterenol), antihypertensives (methyldopa, clonidine, guanabenz, moxonidine and thiazides), vasodilators (nitrates), drugs for heart failure (beta-blockers, ACE inhibitors, angiotensin II receptor blockers and hydralazine), lipid modifying drugs (fibrates and ezetimibe), inotropic and chronotropic drugs (isoproterenol, epinephrine, beta-blockers and calcium channel blockers), vasoconstrictors (ergot alkaloids and vasopressin), anesthetics (sevoflurane, ketamine and propofol), antiepileptic drugs (benzodiazepines, barbiturates and hydantoin), sedative-hypnotics (anticholinergics, antihistamines, antispasmodics, barbiturates, benzodiazepines, bromides, chloral hydrate, ethanol and opioids), psychotropic drugs (antidepressants and antipsychotics), peripheral nervous system drugs (acetylcholinesterase and capsaicin inhibitors), antidyskinetic drugs (dopaminergic agents), acid-base agents (sodium lactate and bicarbonate), bone metabolism agents (parathyroid hormone and bisphosphonates), electrolytes (hypertonic saline and magnesium hydroxide), glycemic agents (insulin and hypoglycemic agents), steroid hormones (dexamethasone), thyroid agents (iodine and lithium), antihyperuricemic agents (xanthine oxidase and urate oxidase inhibitors), gastrointestinal agents (opiates, cholecystokinin and ceruletide), hematological agents (erythropoietin, vitamin $\mathrm{K}$ antagonists and adenosine diphosphate receptor inhibitors), bronchodilators (short- and long-acting betaadrenergic bronchodilators), dermatological agents (histamine receptor inhibitors, high-intensity long-wave ultraviolet light and 8-methoxypsoralen), and more. ${ }^{19}$

For Bond, ${ }^{14}$ a possible hypothesis to explain the functioning of paradoxical pharmacology is the "difference between acute and chronic effects of drugs." Reiterating that the acute and chronic responses to drugs may differ substantially, often being of opposite natures, he proposes that "the exacerbation of a disease can make the compensatory and redundant mechanisms of the organism achieve a beneficial long-term response." This is particularly evident in events mediated by receptors: acute exposure to inhibitors can produce receptor activation and increased signaling, while chronic exposure can produce receptor desensitization and decreased signaling. The same phenomenon occurs with receptor inhibitors.

Similar to the homeopathic method of treatment, which uses ultra-diluted doses of medicines with the aim of avoiding possible aggravation of the illness after application of therapeutic similarity, as a general rule, proponents of paradoxical pharmacology suggest starting with "very small doses, increasing them gradually over the following weeks." 14

Exemplifying the therapeutic use of the paradoxical reactions of the organism, the authors describe clinical conditions which can be treated using this proposal. Congestive heart failure (CHF) is a disease related to impaired cardiac contractility, in which the acute use of beta-adrenergic receptor inhibitors increases cardiac contractility, improves hemodynamics and reduces related symptoms. However, chronic use results in increased mortality. On the other hand, while the short-term use of beta-adrenergic antagonists (beta-blockers: carvedilol, metoprolol, bisoprolol, among others) decreases contractility and exacerbates the $\mathrm{CHF}$, causing the worsening of the illness, long-term use results in increased cardiac contractility and decreased mortality. ${ }^{14,18-20}$ The same is observed with calcium channel blockers. ${ }^{21}$

Similarly, beta-adrenergic agonists are the most potent bronchodilators and play an important role in all stages of asthma management. However, as mentioned in the study of the rebound effect, chronic use is associated with irreversible and fatal paradoxical bronchospasms. On the other hand, while short-term use of beta-adrenergic antagonists leads to bronchoconstriction and worsening of asthma, long-term use leads to bronchodilation and increased asthma management. ${ }^{14,18,22,23}$

Additional examples include the use of methylphenidate (a central nervous system stimulant) in the treatment of ADHD and the use of 5-HT1A serotonin receptor agonists (mediators of hyperalgesia) to produce analgesia. ${ }^{18}$ Of ancient knowledge, the use of thiazide class diuretics provides a paradoxical antidiuretic benefit in the treatment of diabetes insipidus, reducing polyuria and increasing urine osmolality. ${ }^{24}$

Arsenic trioxide $\left(\mathrm{As}_{2} \mathrm{O}_{3}\right)$, an important carcinogen, has been used by homeopathy for more than two centuries as an adjuvant drug in the treatment of several types of cancer, and is being used by paradoxical pharmacology as a promising anticancer drug, ${ }^{25,26}$ mainly in the relapse of acute promyelocytic leukemia, ${ }^{41,42}$ including in Brazil $^{43,44}$ among other applications. ${ }^{19}$

\section{THERAPEUTIC USE OF THE REBOUND EFFECT OF MODERN DRUGS: "NEW HOMEOPATHIC MEDICINES"27-33}

Reiterating that homeopathic treatment has the prerogative of using drugs that cause pathogenetic manifes- 
tations (signs, symptoms, physiological or pathological changes, etc.) similar to disorders requiring treatment, it can be applied with any substance (natural or synthetic) and at any dose (by massive or infinitesimal), provided this principle of similarity is observed. Thus, conventional drugs can be employed according to the homeopathic premises provided they cause primary effects (therapeutic, adverse or collateral effects) similar to the totality of individual characteristic manifestations.

In this proposal, ${ }^{27-33}$ we are suggesting the use of the rebound effect of modern drugs in a curative manner, administering ultra-diluted doses (dynamized medicines) to patients of the drugs that cause a set of similar adverse events in phases I-IV pharmacological clinical trials, proposing to stimulate a homeostatic response of the organism against its own disorders.

To make this project possible, a Homeopathic Materia Medica of Modern Drugs ${ }^{29}$ was elaborated, systematizing all of the primary or pathogenic effects (therapeutic, adverse and collateral effects) to 1,250 modern drugs described in The United States Pharmacopeia Dispensing In formation (USPDI), ${ }^{45}$ according to an anatomical and functional distribution (systems or tracts) and in accordance with the dynamics used in the chapters of the classic Homeopathic Materia Medica. ${ }^{46}$

In order to facilitate the selection of the individualized medicines according to the totality of manifestations similar to the patient-disease binomial, an essential premise for the success of homeopathic treatment, the second stage of the project involved the elaboration of a Homeopathic Repertory of Modern Drugs, ${ }^{29}$ where the pathogenetic effects and their corresponding medicines are organized in the same anatomical/functional distribution, following the arrangement of the classic homeopathic repertories. ${ }^{47}$

Titled New Homeopathic Medicines: Use of Modern Drugs According to the Principle of Similitude, ${ }^{29}$ this project is described and systematized in three digital compendia (Scientific Basis of the Principle of Similitude in Modern Pharmacology, Homeopathic Materia Medica of Modern Drugs and Homeopathic Repertory of Modern Drugs) provided on a bilingual site with free access (http://www.newhomeopathicmedicines.com), allowing the proposal to be known and applied by all interested colleagues.

Exemplifying this possible 'off label' use of numerous classes of modern drugs according to the principle of therapeutic similarity, dozens of therapeutic drugs that show increased blood pressure as primary effect (adalimumab, cyclosporine, dopamine and anti-inflammatory drugs, among others) could be used homeopathically to treat hypertension, provided that other primary or patho- genetic effects of the drug present similarity with the set of signs and symptoms of the individual patient. Respecting this individualization of medicine, drugs that increase blood glucose (amprenavir, corticotropin, diazoxide and estrogens, and more) could be employed homeopathically to treat diabetes; drugs that cause inflammation of the gastric mucosa (abacavir, anti-inflammatory drugs, carbidopa and cilostazol, among others) could be employed homeopathically to treat gastritis and gastric ulcers; medicines that cause immunosuppression (cyclosporins, corticoids and immunosuppressants, and more) could be employed to stimulate the immune system of immunosuppressed patients; among others. Table 1 describes some examples of possible applications of therapeutic similarity with modern drugs in disorders, diseases and syndromes, in accordance with the adverse events caused by such on the various systems or tracts of individuals and described in phase I-IV pharmacological clinical trials. ${ }^{29,45}$

\section{USE OF DYNAMIZED ESTROGEN IN THE TREATMENT OF CHRONIC PELVIC PAIN ASSOCIATED WITH ENDOMETRIOSIS}

Endometriosis is a chronic inflammatory disease characterized by the implantation and proliferation of endometrial tissue in extrauterine locations, causing chronic pelvic pain that is difficult to control. As the main pathophysiological aspect, it is worth mentioning that endometriosis is an estrogen-dependent disease. Putting into practice the proposal described above, we developed a clinical research protocol to assess the effect of dynamized estrogen in the treatment of endometriosis-associated pelvic pain (dysmenorrhea, deep dyspareunia, non-cyclic pelvic pain, cyclic bowel pain and/or cyclic urinary pain).

In the study of modern drugs according to the USPDI ${ }^{45}$ and, consequently, in the Homeopathic Repertory of Modern Drugs (Chapter "Female Genitalia"), ${ }^{29}$ we find a description of the specific pathological sign of endometriosis ("endometrial proliferation or hyperplasia") as an adverse event in four classes of conventional drugs (systemic and vaginal estrogens, tamoxifen and toremifene) (Table 2).

One of those drugs, "systemic estrogen," presents a set of adverse events (pathogenetic effects) that are quite similar to the main manifestations of endometriosis syndrome (endometrial proliferation, dysmenorrhea, dyspareunia, abdominal pain, depression, anxiety, insomnia and migraine, among others) (Table 3), and was selected for the study due to this particularity (individualization of the medicine).

In this randomized, double-blind and placebo controlled trial (RCT), 50 patients with endometriosis, chronic pelvic pain refractory to conventional hormone thera- 
TABLE 1 Possible applications of therapeutic similitude with modern drugs.

Anatomical and Possible applications of therapeutic similitude (Adverse events or pathogenetic effects

functional distribution

Mind/psyche caused in individuals) agitation, amnesia, anxiety, coma, delirium, dementia, depression, disorientation, memory lapses, hyperactivity,

Head irritability, lethargy, mania, nervousness, panic, schizophrenia, suicidal disposition, and more

gait disorders, orthostatic hypotension, syncope, instability, and more

Eyes astigmatism, atrophies, bleeding, cataract, chemosis, corneal diseases, dryness, glaucoma, inflammation, keratopathy, necrosis, neuritis, nystagmus, papilledema, paralysis, pupil disorders, retinal disorders, and more

Vision amblyopia, blindness, diplopia, hyperopia, myopia, presbyopia, scotoma, and more

Hearing tinnitus, deafness, hyperacusis, hearing loss, and more

Nose congestion, coryza, dryness, epistaxis, rhinitis, sinusitis, sneezing, and more

Face

Mouth motor tics, heat waves, hirsutism, neuritis, paralysis, swelling, trismus, and more

disorders, ulcers, and more

Throat angioedema, dryness, dysphagia, esophagitis, pharyngitis, ulcers, and more

Outer throat goiter, heat waves, thyroid disorders, lymphadenopathy, parotitis, pain/stiff neck, and more

Stomach anorexia, dyspepsia, eructation, gastritis, gastroenteritis, hemorrhage, hiccups, nausea, polydipsia, reflux, ulcer, vomiting, and more

Abdomen ascites, appendicitis, cholecystitis, cholestasis, cirrhosis, colitis, gastroenteritis, hemorrhage, liver disorders (failure, necrosis, steatosis, hepatitis, hepatomegaly), paralytic ileus, inflammatory bowel disease, intestinal obstruction or perforation, malabsorption syndrome, pancreatitis, peritonitis, splenomegaly, tumors, and more

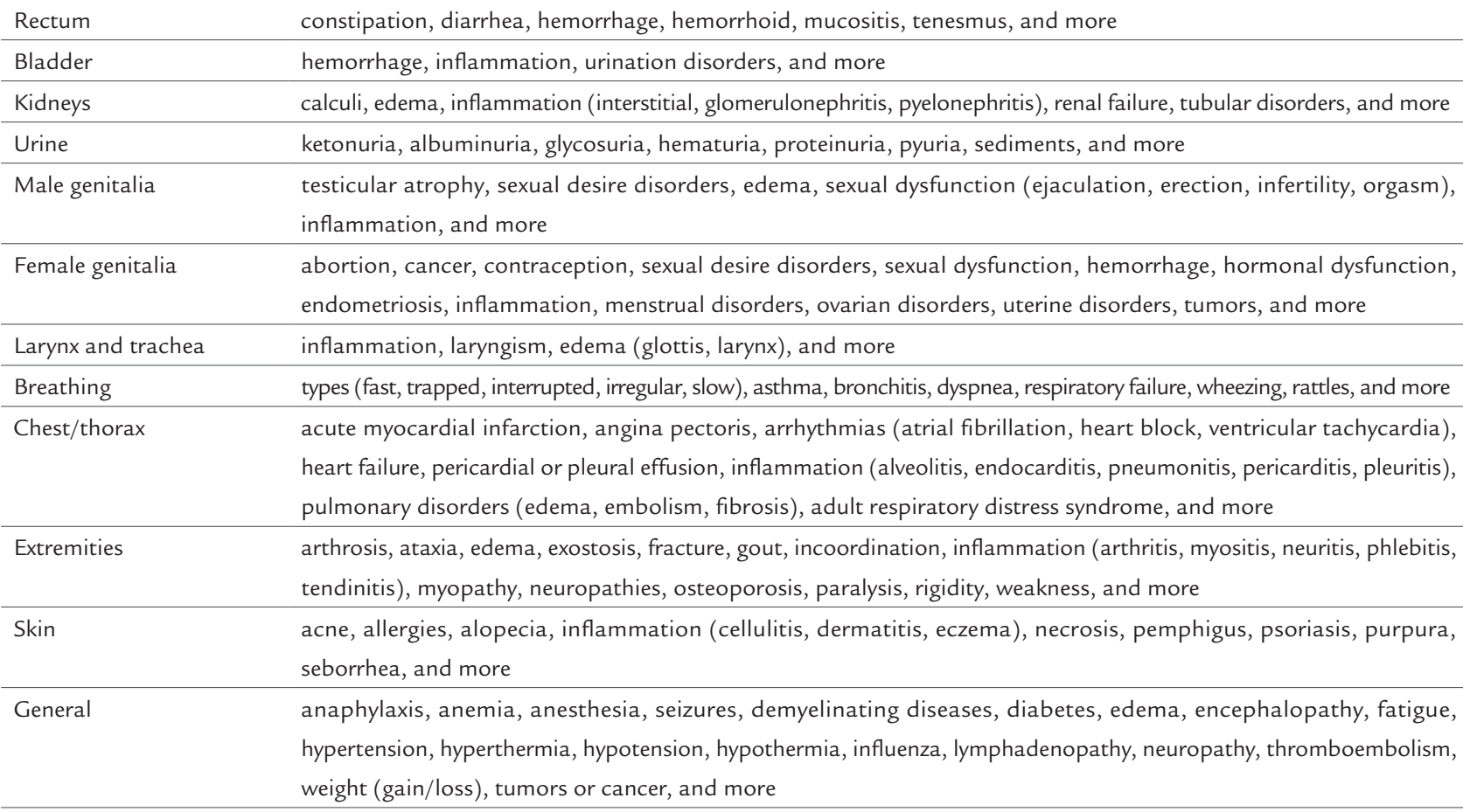

TABLE 2 Endometriosis in the Homeopathic Repertory of Modern Drugs (Chapter "Female Genitalia") ${ }^{29}$

Endometrium

Endometriosis; disorder, endometrial; proliferation, endometrial; hyperplasia: DrosE-syst., Estro-syst., Estro-vag., Tamo-syst., Tore-syst.

DrosE-syst.: drospirenone and estradiol (systemic); Estro-syst.: estrogens (systemic); Estro-vag.: estrogens (vaginal); Tamo-syst.: tamoxifen (systemic); Tore-syst.: toremifene (systemic). 
TABLE 3 Adverse events or pathogenetic effects of estrogen (systemic).

\begin{tabular}{|c|c|}
\hline $\begin{array}{l}\text { Anatomical } \\
\text { and functional } \\
\text { distribution }\end{array}$ & $\begin{array}{l}\text { Adverse events or pathogenetic effects of estrogen } \\
\text { (The United States Pharmacopeia Dispensing Information })^{45} \\
\text { (Homeopathic Materia Medica of Modern Drugs) }^{29}\end{array}$ \\
\hline Mind/psyche & anxiety; depression; emotional lability; dementia; irritability; nervousness \\
\hline Head & headache; migraine; dizziness; embolic stroke; chorea; worsening of epilepsy; hair loss \\
\hline Eyes & Herpes simplex; contact lens intolerance; increased corneal curvature (changes in vision); optic neuritis; retinal vein occlusion (thrombosis) \\
\hline Vision & visual disturbances \\
\hline Nose & sinusitis; nasopharyngitis; rhinitis; nasal congestion; herpes simplex \\
\hline Face & acne; hirsutism; herpes simplex; neuritis; chorea \\
\hline Tongue & chorea \\
\hline Teeth & $\underline{\text { abscesses }}$ \\
\hline Throat & nasopharyngitis; pharyngitis \\
\hline Outer throat & neck pain \\
\hline Stomach & anorexia; dyspepsia; nausea; gastroenteritis; vomit; changes in appetite \\
\hline Abdomen & bloating, flatulence and abdominal cramps; gastroenteritis; biliary obstruction; pancreatitis; liver changes (hemangioma; enzymes) \\
\hline Rectum & constipation; diarrhea \\
\hline Bladder & urinary tract infection \\
\hline Kidneys & urinary tract infection \\
\hline Female genitalia & $\begin{array}{l}\text { amenorrhea; dysmenorrhea; vaginitis; fungal vaginosis; } \text { metrorrhagia; dyspareunia; vaginal hemorrhage; candidiasis; } \underline{\text { herpes simplex; }} \\
\text { increased libido; menorrhagia; stains; endometrial atrophy; endometrial or ovarian cancer; cervical ectropion; endometrial hyperplasia; uterine } \\
\text { leiomyoma; changes in cervical mucus }\end{array}$ \\
\hline Breathing & bronchitis; asthma exacerbation \\
\hline Coughing & increase in coughing \\
\hline Chest/thorax & $\begin{array}{l}\text { bronchitis; increased breast size, sensibility or pain; gynecomastia; pleural infection; chest pain; breast cancer; fibroadenomas; } \\
\text { pulmonary embolism; galactorrhea; myocardial infarction; palpitation; arrhythmias; coronary artery diseases }\end{array}$ \\
\hline Back & pain \\
\hline Extremities & peripheral edema; cramps; muscle spasms; osteoarthritis; neuritis; chorea; worsening of varicose veins \\
\hline Sleep & insomnia \\
\hline Skin & irritation; pruritus; rashes; redness; acne; hirsutism; chloasma; hemorrhagic rash; erythema multiforme; erythema nodosum; melasma \\
\hline General & $\begin{array}{l}\text { asthenia; flu syndrome; hypersensitivity reactions; infections; pain; weight gain; fatigue; hepatitis; hypertension; hypoesthesia; } \\
\text { thromboembolism; hypocalcemia; cholestatic jaundice; worsening of systemic lupus erythematosus; worsening of porphyria; sodium retention; } \\
\text { diabetes or reduced glucose tolerance; thrombophlebitis; increased triglycerides }\end{array}$ \\
\hline
\end{tabular}

Markdown text (font/letter style) to describe adverse events corresponds to their incidence frequency (\%) within the population (USPDI, phase I-IV clinical trials): score $4 /$ bold ( $\geq 4 \%$ ); score $3 /$ italic and underlined (1-4\%); score $2 /$ italic (< $1 \%)$; score $1 /$ normal (overdose).

py and a set of signs and symptoms similar to the adverse events or pathogenetic effects of estrogen (Table 3) were recruited at the Endometriosis Sector of the Clinical Gynecology Division of the University of São Paulo Medical School's Hospital das Clínicas (HC-FMUSP). The selection process was carried out through an analysis of patient records and responses to structured questionnaires. After meeting the inclusion criteria, the patients were distributed randomly to receive dynamized estrogen or placebo, while maintaining conventional hormone therapy. The primary clinical outcome was the severity of the chronic pelvic pain after 24 weeks of intervention. ${ }^{48,49}$ The results of this recently published RCT showed that dynamized estrogen was significantly more effective than placebo for reducing endometriosis-associated pelvic pain (dysmenorrhea, non-cyclic pelvic pain and cyclic bowel pain), improving quality of life (bodily pain, vitality and mental health) and reducing depressive symptoms. ${ }^{50}$

In a similar proposal described in another recently published paper ${ }^{51}$ that demonstrated worsening of psoriasis (rebound psoriasis) after discontinuation of immunomodulatory drugs (T-cell modulators and TNF inhibitors), we suggest the treatment of psoriasis with drugs that cause psoriasis as an adverse event (beta-ad- 
renergic blocking agents, lithium and antimalarial agents, among others) corresponding with the use of dynamized estrogen to treat endometriosis.

\section{Conclusion}

Describing the undesirable effects of the indiscriminate use of drugs that act according to the principle of contraries, opposite to the principle of similars, Hahnemann warned of the risks of secondary action (rebound effect or paradoxical reaction) of the organism, validating the principle of similarity through the Aristotelian syllogism (modus tollens, denying the consequent or indirect proof):

If these ill-effects are produced, as may very naturally be expected from the antipathetic employment of medicines, the ordinary physician imagines he can get over the difficulty by giving, at each renewed aggravation, a stronger dose of the remedy, whereby an equally transient suppression is effected; and as there then is a still greater necessity for giving ever-increasing quantities of the palliative there ensues either another more serious disease or frequently even danger to life and death itself, but never a cure of a disease of considerable or of long standing. (Organon of medicine, $§ 60)^{36}$

With modern drugs, a large number of iatrogenic events could be avoided if health professionals paid attention to the possible occurrence of the rebound effect or paradoxical reaction of the organism, ${ }^{13}$ minimizing the aggravation of clinical conditions with the slow and gradual decrease of doses. Although not included in conventional adverse events of drug, "effects from the discontinuation of drugs are part of the pharmacology of the drug" 52 and should be incorporated into the teaching of modern pharmacology.

On the other hand, by employing the rebound effect of conventional drugs in a curative manner, we can expand the spectrum of therapeutic similarity with hundreds of "new homeopathic medicines," including signs and symptoms that are absent in classic homeopathic pathogenetic trials and allowing the application of homeopathic treatment for a multitude of diseases, disorders and syndromes.

As has been suggested by the propagators of homeopathic therapy for more than two centuries, ${ }^{28,33}$ Bond and Giles ${ }^{18}$ encourage researchers to examine the paradoxical phenomenon (rebound effect) without prejudice and to challenge the dogma of current treatment paradigms with new therapeutic approaches, despite the difficulty in accepting new ideas by our peers.

\section{Resumo}

Uso terapêutico do efeito rebote dos fármacos modernos: "Novos medicamentos homeopáticos"

O tratamento homeopático está fundamentado no princípio da similitude terapêutica, empregando medicamentos que causam determinados distúrbios para tratar manifestações semelhantes, estimulando uma reação do organismo contra seus próprios transtornos. A ocorrência dessa reação secundária do organismo, de natureza oposta à ação primária dos medicamentos, está evidenciada no estudo do efeito rebote (paradoxal) de inúmeras classes de fármacos modernos. Neste trabalho, além de fundamentar o princípio da similitude perante a farmacologia clínica e experimental, sugerimos uma proposta para empregar centenas de drogas convencionais segundo o método homeopático, aplicando a similitude terapêutica entre os eventos adversos dos medicamentos e as manifestações clínicas dos pacientes. Descrevendo linhas de pesquisa existentes e um método específico para o uso terapêutico do efeito rebote dos fármacos modernos (http://www.novosmedicamentoshomeopaticos.com), esperamos minimizar preconceitos relativos à homeopatia e contribuir para uma ampliação da arte de curar.

Palavras-chave: homeopatia, farmacologia, ação farmacodinâmica do medicamento homeopático, lei dos semelhantes, efeito rebote, medicamentos homeopáticos novos.

\section{References}

1. Teixeira MZ. Scientific evidence of the homeopathic epistemological model. Int J High Dilution Res. 2011; 10(34):46-64.

2. Teixeira MZ. Semelhante cura semelhante: o princípio de cura homeopático fundamentado pela racionalidade médica e científica [Like cures like: the homeopathic cure principle based on medical and scientific reason]. São Paulo: Editorial Petrus; 1998. Available from: http://www.homeozulian.med br/homeozulian_visualizarlivroautor.asp?id=3

3. Teixeira MZ. Similitude in modern pharmacology. Br Homeopath J. 1999; 88(3):112-20.

4. Teixeira MZ. Evidence of the principle of similitude in modern fatal iatrogenic events. Homeopathy. 2006; 95(4):229-36.

5. Teixeira MZ. NSAIDs, Myocardial infarction, rebound effect and similitude. Homeopathy. 2007; 96(1):67-8.

6. Teixeira MZ. Bronchodilators, fatal asthma, rebound effect and similitude Homeopathy. 2007; 96(2):135-7.

7. Teixeira MZ. Antidepressants, suicidality and rebound effect: evidence of similitude? Homeopathy. 2009; 98(1):114-21.

8. Teixeira MZ. Statins withdrawal, vascular complications, rebound effect and similitude. Homeopathy. 2010; 99(4):255-62.

9. Teixeira MZ. Rebound acid hypersecretion after withdrawal of gastric acid suppressing drugs: new evidence of similitude. Homeopathy. 2011; 100(3):148-56

10. Teixeira MZ. Rebound effect of drugs: fatal risk of conventional treatment and pharmacological basis of homeopathic treatment. Int J High Dilution Res. 2012; 11(39):69-106. 
11. Teixeira MZ. Antiresorptive drugs (bisphosphonates), atypical fractures and rebound effect: new evidence of similitude. Homeopathy. 2012; 101(4):231-42.

12. Teixeira MZ. Immunomodulatory drugs (natalizumab), worsening of multiple sclerosis, rebound effect and similitude. Homeopathy. 2013; 102(3):215-24

13. Teixeira MZ. Rebound effect of modern drugs: serious adverse event unknown by health professionals. Rev Assoc Med Bras (1992). 2013; 59(6):629-38.

14. Bond RA. Is paradoxical pharmacology a strategy worth pursuing? Trends Pharmacol Sci. 2001; 22(6):273-6.

15. Yun AJ, Lee PY, Bazar KA. Paradoxical strategy for treating chronic diseases where the therapeutic effect is derived from compensatory response rather than drug effect. Med Hypotheses. 2005; 64(5):1050-9.

16. Page C. Paradoxical pharmacology: turning our pharmacological models upside down. Trends Pharmacol Sci. 2011; 32(4):197-200.

17. Davies CJ, Davies DM. Paradoxical reactions to commonly used drugs. Adverse Drug React Bull. 2001; 211:807-10.

18. Bond RA, Giles H. For the love of paradox: from neurobiology to pharmacology. Behav Pharmacol. 2011; 22(5-6):385-9.

19. Smith SW, Hauben M, Aronson JK. Paradoxical and bidirectional drug effects. Drug Saf. 2012; 35(3):173-89.

20. Bristow MR. Beta-adrenergic receptor blockade in chronic heart failure Circulation. 2000; 101(5):558-69.

21. de Vries RJ, van Veldhuisen DJ, Dunselman PH. Efficacy and safety of calcium channel blockers in heart failure: focus on recent trials with second-generation dihydropyridines. Am Heart J. 2000; 139(2 Pt 1):185-94.

22. Bond RA, Spina D, Parra S, Page CP. Getting to the heart of asthma: can "beta blockers" be useful to treat asthma? Pharmacol Ther. 2007; 115(3):360-74.

23. Dickey BF, Walker JK, Hanania NA, Bond RA. Beta-adrenoceptor inverse agonists in asthma. Curr Opin Pharmacol. 2010; 10(3):254-9.

24. Loffing J. Paradoxical antidiuretic effect of thiazides in diabetes insipidus: another piece in the puzzle. J Am Soc Nephrol. 2004; 15(11):2948-50.

25. Cui X, Kobayashi Y, Akashi M, Okayasu R. Metabolism and the paradoxica effects of arsenic: carcinogenesis and anticancer. Curr Med Chem. 2008 15(22):2293-304.

26. Platanias LC. Biological responses to arsenic compounds. J Biol Chem. 2009; 284(28):18583-7.

27. Teixeira MZ. Homeopathic use of modern medicines: utilisation of the curative rebound effect. Med Hypotheses. 2003; 60(2):276-83.

28. Teixeira MZ. 'Paradoxical strategy for treating chronic diseases': a therapeutic model used in homeopathy for more than two centuries. Homeopathy. 2005; 94(4):265-6.

29. Teixeira MZ. New homeopathic medicines: use of modern drugs according to the principle of similitude. São Paulo: Marcus Zulian Teixeira. 3v. 2010 Available from: http://www.newhomeopathicmedicines.com

30. Teixeira MZ. New homeopathic medicines: use of modern drugs according to the principle of similitude. Homeopathy. 2011; 100(4):244-52.

31. Teixeira MZ. Homeopathic use of modern drugs: therapeutic application of the organism paradoxical reaction or rebound effect. Int J High Dilution Res. 2011; 10(37):338-52.

32. Teixeira MZ. 'New Homeopathic Medicines' database: a project to employ conventional drugs according to the homeopathic method of treatment. Eur J Integr Med. 2013; 5(3):270-8.

33. Teixeira MZ. 'Paradoxical pharmacology': therapeutic strategy used by the 'homeopathic pharmacology' for more than two centuries. Int J High Dilution Res. 2014; 13(48):207-26

34. Teixeira MZ. Homeopatia: prática médica coadjuvante. Rev Assoc Med Bras. 2007; 53(4):374-6.
35. Hahnemann S. Essay on a new principle for ascertaining the curative power of drugs, with a few glances at those hitherto employed. In: Dudgeon RE. The lesser writings of Samuel Hahnemann. New Delhi: B. Jain Publishers; 1995 (Reprint edition).

36. Hahnemann S. Organon of medicine. 6. ed. (Translated by William Boericke). New Delhi: B Jain Publishers; 1991. Available from: http://homeoint.org/ books/hahorgan/index.htm

37. Teixeira MZ. Brief homeopathic pathogenetic experimentation: a unique educational tool in Brazil. Evid Based Complement Alternat Med. 2009; 6(3):407-14

38. Teixeira MZ. Protocolo de experimentação patogenética homeopática em humanos [Protocol of homeopathic pathogenetic trial in humans]. Rev Med (São Paulo). 2013; 92(4):242-63

39. Kovács I. Examination of the rebound effect of biphasic oral contraceptives. Ther Hung. 1990; 38(3):110-3.

40. Seeman P, Madras B. Methylphenidate elevates resting dopamine which lowers the impulse-triggered release of dopamine: a hypothesis. Behav Brain Res. 2002; 130(1-2):79-83

41. Sanz MA, Grimwade D, Tallman MS, Lowenberg B, Fenaux P, Estey EH, et al. Management of acute promyelocytic leukemia: recommendations from an expert panel on behalf of the European LeukemiaNet. Blood. 2009; 113(9):1875-91.

42. Kwaan HC. The unique hemostatic dysfunction in acute promyelocytic leukemia. Semin Thromb Hemost. 2014; 40(3):332-6.

43. Jácomo RH, Figueiredo-Pontes LL, Rego EM. [From the molecular model to the impact on prognosis: an overview on acute promyelocytic leukemia] Rev Assoc Med Bras. 2008; 54(1):82-9.

44. Ministério da Saúde. Secretaria de Ciência, Tecnologia e Insumos Estratégicos. Departamento de Gestão e Incorporação de Tecnologias em Saúde. Relatório de Recomendação da Comissão Nacional de Incorporação de Tecnologias no SUS - CONITEC - 129. Trióxido de arsênio para o tratamento da leucemia promielocítica aguda (LPA). 2014. Available from: http://conitec.gov.br/ images/Consultas/Relatorios/2014/Relatorio_TrioxidoArsenio-CP.pdf

45. The United States Pharmacopeial Convention. The United States Pharmacopeia Dispensing Information. 24. ed. Easton: Mack Printing Co.; 2004.

46. Kent JT. Lectures on Homoeopathic Materia Medica. New Delhi: B. Jain Publishers; 2011. Available from: http://homeoint.org/books3/kentmm/ index.htm.

47. Kent JT. Repertory of the Homoeopathic Materia Medica. New Delhi: B. Jain Publishers; 2008. Available from: http://homeoint.org/books/kentrep/ index.htm.

48. Teixeira MZ, Podgaec S, Baracat EC. Homeopathic treatment of chronic pelvic pain in women with endometriosis. ClinicalTrials.gov Identifier: NCT02427386. Available from: https://clinicaltrials.gov/show/NCT02427386

49. Teixeira MZ, Podgaec S, Baracat EC. Protocol of randomized controlled trial of potentized estrogen in homeopathic treatment of chronic pelvic pain associated with endometriosis. Homeopathy. 2016; 105(3):240-9.

50. Teixeira MZ, Podgaec S, Baracat EC. Potentized estrogen in homeopathic treatment of endometriosis-associated pelvic pain: A 24-week, randomized, double-blind, placebo-controlled study. Eur J Obstet Gynecol Reprod Biol. 2017; 211:48-55

51. Teixeira MZ. Biological therapies (immunomodulatory drugs), worsening of psoriasis and rebound effect: new evidence of similitude. Homeopathy. 2016; 105(4):344-5.

52. Reidenberg MM. Drug discontinuation effects are part of the pharmacology of a drug. J Pharmacol Exp Ther. 2011; 339(2):324-8. 